\title{
Maternal and Foetal Outcome of Eclampsia in Mymensingh Medical College Hospital
}

\author{
Sultana Afroj
}

\begin{abstract}
:
This prospective cross-sectional study is undertaken to evaluate the maternal and foetal outcome of patients admitted in Mymensingh Medical College Hospital from November 2002 to April 2003. Among 5175 obstetric patients admitted to the hospital, 212 were eclamptic, yielding an incidence of $4.1 \%$. The antepartum, intrapartum and postpartum incidences of eclampsia were $50 \%, 26.5 \%$ and $23.5 \%$ respectively. Among the patients with eclampsia, $56.85 \%$ had good prognosis without any added complication and $45.85 \%$ had complications. The case fatality rate of eclampsia was $5 \%$, which was lower than that of the previous studies. In this study out of 200 patients, foetal death was $23.98 \%$. Changing the ante convulsant from diazepam to magnesium sulfate the incidence of death in eclampsia patients have significantly reduced.. But reduction of the risk of death was difficult when patients had developed complications. Most of the patient who died was in complicated group, these complications developed as a result of a delayed treatment. Therefore, efforts should be directed at developing awareness to receive treatment at an appropriate time to reduce the mortality from eclampsia and its complications.
\end{abstract}

Key words: Eclampsia, Maternal outcome, Foetal outcome.

\section{Introduction:}

Eclampsia is described as a clinical condition associated with pregnancy complicated by preeclampsia. It remains an important cause of maternal mortality throughout the world, accounting for about 50,000 deaths worldwide ${ }^{1}$. In developed countries, eclampsia complicates about 1 in 2000 deliveries $^{2}$. In developing countries, the prevalence of eclampsia varies widely, from 1 in 100 to 1 in $1700^{3-5}$. It is a common problem in developing countries because illiteracy, lack of health awareness, poverty, bad communication, poor linkage of community with comprehensive health facilities and superstitious beliefs prevent women from seeking medical advice during pregnancy.

The incidence of eclampsia is extraordinarily high in Bangladesh (7.9\%), according to the results of a house-to-house survey ${ }^{6}$. In this country, only $2.3 \%$ women end their pregnancy under medical supervision (whether it be abortion or delivery) ${ }^{7}$, the rest have no access to obstetric care. As a result, most preeclampsia cases remains unrecognized until severe complications, such as eclampsia occurred.

Junior Consultant (Gynae), Shaheed Suhrawardi Medical College \&

Hospital, Dhaka

Correspondence:

Dr.Sultana Afroj

Junior Consultant (Gynae), Shaheed Suhrawardi Medical College \&

Hospital, Dhaka
Eclampsia is one of the major cause of maternal death in Bangladesh $(16 \%)^{8}$. In developing countries,eclampsia has become the prime killer, indicating that death from eclampsia is particularly difficult to prevent ${ }^{9}$. Patients with eclampsia, develop complications because they reach the hospital late and the complications are so severe that in most cases they are irreversible. On the other hand when maternal life is in danger since the universal decision is to sacrifice the baby, the foetal mortality is also very high in eclampsia.

Until recently, the treatment of eclampsia varied throughout the world. A large multi-center study has shown that magnesium sulfate is the ideal anticonvulsant ${ }^{10}$. The more current Magpie trial11, in which Bangladesh was one of the participating countries, showed that magnesium sulfate reduced the risk of developing eclampsia. Now in spite of standard protocol for management of eclampsia, many lives are still lost due to delay in the arrival of the patients at the comprehensive health care centre. This study will help us to make a situation analysis of eclampsia and recommend action plan to improve the condition in our country.

\section{Materials: \\ Study design:}

It was a prospective cross-sectional study.

Maternal and Foetal Outcome of Eclampsia m Mymensingh Medical College Hospital 


\section{Place of study:}

Eclampsia Ward in the Department of Obstetrics and Gynaecology, Mymensingh Medical College Hospital, Mymensingh

\section{Study period:}

In the period of November, 2002 to April, 2003

\section{Sample size:}

Two hundred eclampsia patients admitted to $\mathrm{MMCH}$ and fulfilling the inclusion criteria constituted the study population.

\section{Inclusion criteria:}

Eclampsia patient admitted during the study period who stayed in hospital at least for 7 days.

\section{Exclusion criteria:}

Eclampsia patients who were discharged within 48 hours of delivery.

\section{Methods:}

Data were collected by using predesigned questionnaire. Since most of the patients were unconscious relevant information were mostly collected by interview of their relatives or attendants and from previous medical record sheets. Diagnosis was confirmed by history, physical examination and urine examination. Convulsion was controlled by Injection Magnesium Sulphate. Severe hypertension was controlled by injection hydralazine and other oral anti-hypertensives. Variables like age, parity, duration of pregnancy, mode of delivery, antenatal check-up and foetal conditions were recorded. The results are illustrated in the form of tables and graphs. All relevant data were complied and entered into computer using computer based software for appropriate analysis in SPSS.

\section{Limitation of the Study:}

a) Since most of the patients were unconscious on arrival at the hospital, history and other relevant information were collected from the patients' attendants. Thus informations might not be 100 percent accurate.

b) Different types of essential investigations were difficult to do on emergency basis due to insufficient investigation facilities in the hospital.

c) As Hospital-stay was only for a short period due to the shortage of bed, probably exact number of perinatal mortality could not be estimated. Only early neonatal deaths which occurred within 7 days of delivery were recorded.

\section{Results:}

Table-1:

Incidence of eclampsia in MMCH, Mymensingh

\begin{tabular}{|l|c|c|}
\hline $\begin{array}{l}\text { Total numbers } \\
\text { admitted }\end{array}$ & $\begin{array}{c}\text { Number of eclamptic } \\
\text { patients }\end{array}$ & Percentage \\
\hline 5175 & 212 & 4.1 \\
\hline
\end{tabular}

Figure-1:

\section{Age distribution}

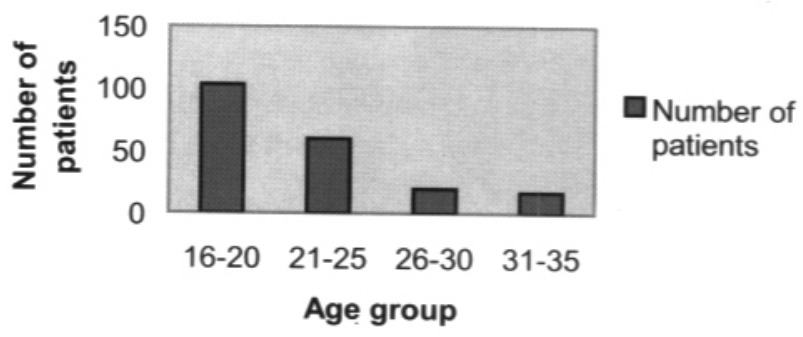

Table-2:

Antenatal Check up ( $\mathrm{n}=200)$

\begin{tabular}{|l|l|l|}
\hline Types & Number of Patients & percentage \\
\hline Regular & 24 & 12 \\
\hline Irregular & 72 & 36 \\
\hline No Visit & 104 & 52 \\
\hline
\end{tabular}

Types of Eclampsia

Figure-2

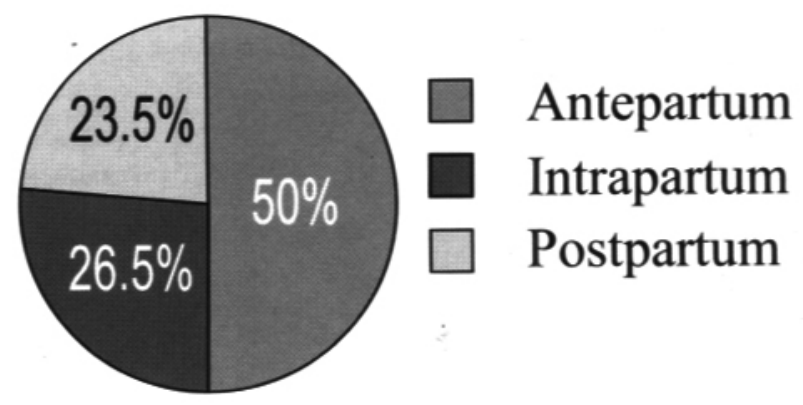




\section{Table-3:}

Distribution of death in different groups of eclampsia $(\mathrm{n}=200)$

\begin{tabular}{|l|l|l|l|l|}
\hline Types & Antepartum & Intrapartum & Postpartu & Total \\
\hline Maternal & $\begin{array}{l}6 \\
(60 \%)\end{array}$ & $1(10 \%)$ & $\begin{array}{l}3 \\
(30 \%)\end{array}$ & 10 \\
\hline Foetal & $\begin{array}{l}25 \\
(53.19 \%)\end{array}$ & $\begin{array}{l}17 \\
(36.17 \%)\end{array}$ & $5(10.63 \%)$ & 47 \\
\hline
\end{tabular}

\section{Table-4 :}

Causes of maternal death in eclampsia $(n=200)$

\begin{tabular}{|l|l|l|}
\hline Causes of death & $\begin{array}{l}\text { Number of } \\
\text { death }\end{array}$ & Percentage \\
\hline Pulmonary oedema & 4 & 40.00 \\
\hline Renal failure & 1 & 10.00 \\
\hline Cerebrovascular accident & 1 & 10.00 \\
\hline Obstetrics shock & 3 & 30.00 \\
\hline Anesthetic hazard & 1 & 10.00 \\
\hline
\end{tabular}

\section{Figure-4}

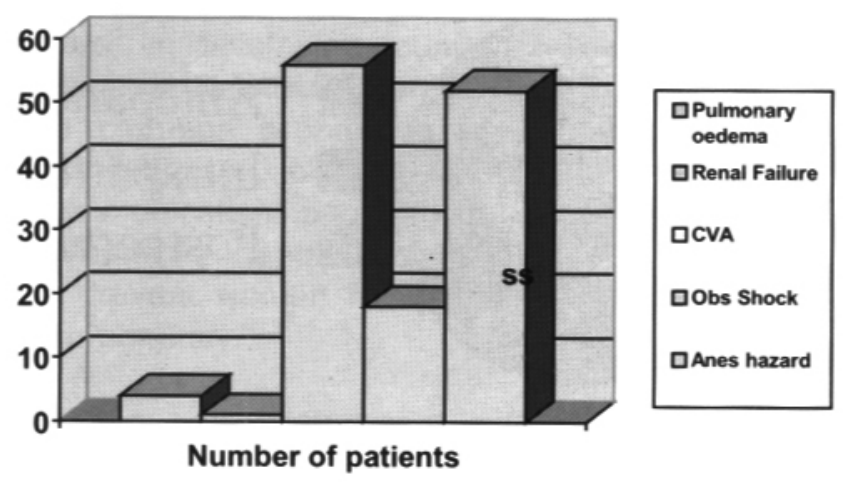

Table-5:

Outcome of Pregnancy

\begin{tabular}{|l|l|l|}
\hline $\begin{array}{l}\text { Condition of the baby at } \\
\text { birth }\end{array}$ & $\begin{array}{l}\text { Number of } \\
\text { baby }\end{array}$ & Percentage \\
\hline Alive & 149 & 76.02 \\
\hline Stillborn & 25 & 12.76 \\
\hline END & 22 & 11.22 \\
\hline
\end{tabular}

Table -6:

Causes of early perinatal death(n=22)

\begin{tabular}{|l|l|l}
\hline Causes & Number of babies & Percentage \\
\hline Asphyxia & 7 & 31.8 \\
\hline Prematurity & 9 & 41 \\
\hline Septicacemia & 3 & 13.6 \\
\hline Jaundice & 3 & 13.6 \\
\hline
\end{tabular}

\section{Discussion:}

During the study period from November 2002 to April 2003 total number of obstetric cases admitted in the Department of Obstetrics and Gynaecology, Mymensingh Medical College Hospital, Mymensingh were 5175. The number of eclampsia cases was 212. So the incidence of eclampsia in $\mathrm{MMCH}$ was $4.1 \%$ (Table 1). The incidence of this study is consistent with national incidence. A study in Dhaka Medical College Hospital in 1988 to 2000 it showed the incidence as $9 \%$. The study which was done at Mitford Hospital in 1990 the incidence was 7.6 percent $^{13}$. Case fatality rate during study period among the patients in eclampsia ward in MMCH was 10 out of 200, so it was $5 \%$. In India it has been found to vary from $2-30 \%$ more in rural based hospital than in urban counterpart. In Bangladesh in a study at Mitford Hospital in 1990 the CPR was $9 \%{ }^{13}$. In a study in DMCH from 1998 to 2000 it was $8.6 \%{ }^{12}$ and in another study at DMCH was $7.7 \%{ }^{14}$. Recently case fatality rate from eclampsia has decreased probably due to availability of potent anticonvulsant like MgSO4 and good nursing care.

In the present study(Fig 1), it was found that $51.5 \%$ mothers were at or below 20 years having maternal death of $20 \%$ and perinatal death of $55.32 \%$. Rest of the patients was above 20 years. Highest maternal death rate of $30 \%$ was seen inpatients at or above 26 years of age. In a study at $\mathrm{DMCH}$ patients below 20 years had death rate of $50 \%{ }^{14}$.

In this study(Fig 2), 100(50\%) patients developed antepartum , 53(26.5\%) intrapartum and 23.5\% postpartum eclampsia. This finding is consistent with the findings of other studies ${ }^{13,15}$.

In this study maternal death was highest in antepartum Eclampsia patients $(60 \%)$ and most common cause of death was preliminary Oedema (40\%) [please compare this statement e' another study]

The perinatal mortality rate in eclamtic patients was $23.9 \%$ in this study. This finding dose not match with findings of other studies, where the PND was shown Maternal and Foetal Outcome of Eclampsia in Mymensingh Medical College Hospital low. The 
explanation of high PN mortality rate in this study can the related to the fact that $\mathrm{MMCH}$ is a tertiary referral Hospital which deals with referred cases from Mymensing and surrounding areas. These particulars are mostly non-booked and travels long distance to reach Hospital.

\section{Conclusion:}

The present study and other similar studies in Bangladesh and India show that Eclampsia still contributes greatly in maternal mortality. If Millennium Development Goal (MDG) 4 has to be achieved the disease Eclampsia must get priority in maternal health. Both treatment and prevention of Eclampsia needs to be strengthened. This is only possible if people particularly women and families in rural areas are made aware about the danger signs of disease, its need for early intervention. Side by side service providers dealing with women's health must be well oriented in the management protocol of Eclampsia and should deal with the patients as per need. Separate Eclampsia Units should be developed in Obstetric Department of each Medical Collage and District Hospital and should be equipped with modern ICU facilities. The staff working in those Units should be well trained to deal with Eclampsia patients.

\section{References}

1. Duley L. Maternal mortality associated with hypertensive disorders of pregnancy in Africa, Asia, Latin America and the Caribbean. Br J Obstet Gynaecol. 1992; 99:547-553.

2. Douglas KA, Redman CWG. Eclampsia in the United Kingdom. BMJ. 1994; 309:1395-1400.

3. World Health Organization. International Collaborative Study of Hypertensive Disorders of Pregnancy. Geographic variation in the incidence of hypertension in pregnancy. Am J Obstet Gynecol. 1988;158:80-83.

4. Crowther CA. Eclampsia at Harare Maternity Hospital. An epidemiological study. S Afr Med J. 1985; 68:927-929.
5. Bergstrom S, Povey G, Songane F, Ching C. Seasonal incidence of eclampsia and its relationship to metereological data in Mozambique. J Perinat Med 1992; 20:153-158.

6. BIRPERT. Bangladesh Institute of Research for Promotion o Essential and Reproductive Health and Technologies. Proceeding; of Dissemination Workshop on Maternal Morbidity study, Hote Sheraton Dhaka; 1994.

7. Yasmin HA, Rahman MH, Chowdhury FK, et al. Baseline surve1 for assessment of emergency obstetric care service in Bangladesh Bangladesh Institute of Research for Promotion of Essential am Reproductive Health and Technologies (BIRPERHT). March 199510.

8. Fauveau V, Konij KA, Chakrabarty J, Chowdhury AL. Causes c maternal mortality in Rural Bangladesh. Bull WHO. 1988; 66:643 651.

9. Redman C. Eclampsia still kills. Br Med J. 1988; 296:12091210 .

10. The Eclampsia Trial Collaborative Group. Which nticonvulsar for women with eclampsia? Evidence from the Collaborativ Eclampsia Trial. Lancet. 1995; 345:1445-1463.

11. Magpie Trial Collaboration Group. Do women with pre eclampsia, and their babies, benefit from magnesium sulphate? Th Magpie Trial: a randomised placebo-controlled trial. Lancet. 2002 359:1877-1890.

12. Mosammat Rashida Begum, Anowara Begum, Ehsan Quadi Sayeba Akter, Latifa Shamsuddin; Eclampsia: Still a problem i Bangladesh. Medscape General Medicine, 2004; 6(4):52

13. Khatun S, Nilufar S, Bhuiyan AB, Begum K: Perinatal outcorm of eclampsia; Bangladesh Journal of Obstetrics and Gynaecolog 1994; 9. 53-60

14. Alam, Irin Parveen, A study on perinatal outcome in eclampsi DMCH(Dissertation), Bangladesh College of Physicians art Surgeon, March 2002.

15. Gaur Kishore Chakravarty, Study SBMC(Dissertation), Bangladesh College Surgeon, September 1996.

16. Moodley J. Treatment of eclampsia. Br J Obstet Gynaeco 1990:97:99-101

17. Loudon I. Some historical aspects of toxaemia of pregnancy. / review. Br J Obstet Gynaecol. 1991:98:853-858

18. Leitch CR, Cameron AD, Walker JJ. The changing pattern c eclampsia over a 60 years period. Br J Obstet Gynaecol. 1997 104:917-922. 